\title{
ТАКТИЧЕСКИЕ МОДЕЛИ КОНКУРЕНЦИИ В ПРЕДПРИНИМАТЕЛЬСКИХ СТРУКТУРАХ НЕСМЕЖНЫХ ОБЛАСТЕЙ, НА ПРИМЕРЕ СФЕРЫ РЕСТОРАННЫХ УСЛУГ И МАССОВОГО ФУТБОЛА
}

\section{TACTICAL MODELS OF COMPETITION IN ENTREPRENEURIAL STRUCTURES OF NON-CONNECTED AREAS, ON THE EXAMPLE OF THE SPHERE OF RESTAURANT SERVICES AND MASS FOOTBALL}

\section{Krasnova \\ R. Akhmedova}

Summary: The article is devoted to the analysis of modern methods of competitive struggle in the segment of private entrepreneurship, namely: restaurant services and grassroots football schools. The features of industry competition are highlighted separately. Similar and distinctive features of tactical models for each segment are also indicated. Special emphasis is placed on the benefits of personal marketing.

Keywords: grassroots football, entrepreneurship, tactical models of competition, restaurant services.
K лючевым понятием, выражающим сущность рыночных отношений, является понятие конкуренции. Эффективность функционирования субъектов хозяйствования в значительной степени зависит от понимания природы конкуренции, форм ее проявления, методов конкурентной борьбы и факторов, определяющих готовность предприятий к такой борьбе [1].

Поскольку каждое предприятие в процессе хозяйственной деятельности является участником конкурентной борьбы за потребителя (покупателя), то один из важных элементов эффективного функционирования для него заключается в определении механизма обеспечения конкурентоспособности, разработке стратегии деятельности с учетом отраслевых особенностей и собственных преимуществ. Не подлежит сомнению тот факт, что каждый субъект хозяйствования должен выработать собственный подход к потребителю, который позволил бы ему занять свою нишу в выбранном сегменте рынка, не нарушая общеотраслевой стратегии развития.

Условия конкуренции в различных отраслях экономики не одинаковы в соответствии с чем возникают

\begin{abstract}
Краснова Марина Юрьевна
Аспирант, старший преподаватель, НОЧУВО «Московский Финансово-Промышленный Университет «Синергия»»

iamkrasnova@mail.ru Ахмедова Римма Рафаильевна Аспирант, НОЧУ ВО «Московский

Финансово-Промышленный Университет «Синергия»;; старший преподаватель, Российский университет дружбы народов rimma.akhmedova@gmail.com

Аннотация: Статья посвящена анализу современных методов ведения конкурентной борьбы в сегменте частного предпринимательства, а именно: ресторанные услуги и школы массового футбола. Отдельно выделены особенности отраслевой конкуренции. Также обозначены схожие и отличительные черты тактических моделей для каждого сегмента. Особый акцент сделан на преимуществах маркетинга персоналий.
\end{abstract}

Ключевые слова: массовый футбол, предпринимательство, тактические модели конкуренции, ресторанные услуги.

индивидуальные конкурентные преимущества предприятий, методы борьбы и реализации стратегии их позиционирования на рынке, что в свою очередь обуславливает существование уникальных, особенных тактических моделей конкуренции в предпринимательских структурах несмежных областей.

В настоящее время современный рынок претерпевает существенных изменений, некоторые из которых трудно объяснить в рамках понятий экономических теорий прошлых лет, в итоге складываются специфические формы конкурентных отношений, изменяется конечная цель конкурентной борьбы. Очевидно, что изучение сущности и особенностей формирования современных конкурентных отношений в различных отраслях промышленности позволяет сделать вывод об изменениях в структуре национальной экономики и предусмотреть тенденции ее развития, а также формализовать актуальные и действенные методы ведения конкурентной борьбы современных предприятий.

В данном контексте особое значение приобретают тактические модели конкуренции, которые представ- 
ляют собой совокупности конкурентных действий, применяемых участниками рынка в течение ограниченного по времени периода взаимодействия с конкретными соперниками (тактическое соперничество) для решения фиксированного круга внутренне связанных между собой задач по применению конкурентного потенциала и достижению желаемых конкурентных результатов. В тоже время, каждое звено тактического взаимодействия с одними на разных конкурентных полях, может приводить к неодинаковым результатам и участникам рынка приходится по-разному использовать различные конкурентные действия, применяя их на постоянной либо временной основе [2].

В этой связи исследование трансформации тактических моделей конкуренции в предпринимательских структурах несмежных областей является своевременным и актуальным, что и предопределяет выбор темы данной статьи.

Основные подходы к методологии исследования конкуренции и конкурентоспособности заложены в трудах таких экономистов как И. Ансофф, М. Портер, Д. Рикардо, А. Смит. Теоретические и методологические основы отношений конкуренции, а также формы их проявления в хозяйственной практике различных предприятий являются предметом исследования отечественных авторов, к числу которых можно отнести: Петрову И.С., Шишмакову Н.С., Леонидова А.В., Серебрянникову С.В. и др.

Основное внимание в данных научных работах уделено определению конкуренции, изучению общей конкурентной ситуации в отдельной отрасли и на рынке, диагностированию конкурентоспособности предприятия, разработке и реализации стратегий конкурентного поведения.

Однако, несмотря на имеющиеся наработки, масштабность и многоаспектность моделей в разных экономических условиях, рыночных ситуациях и отраслевых срезах обуславливает необходимость проведения дальнейших углубленных исследования, что и составляет целевую направленность проводимого исследования.
На первом этапе исследования представляется целесообразным выделить ключевые особенности отраслевой конкуренции в сегменте услуг питания и спортивной подготовки населения (см. табл. 1).

Теперь рассмотрим каким образом отраслевые особенности конкуренции отражаются на тактических моделях ведения рыночной борьбы представителями этих несмежных отраслей.

Наличие большого количества предприятий питания различных типов, реализующих широкий или узкий ассортимент продукции на однородном сегменте рынка, а также относительно свободный вход и выход с рынка позволяют сделать вывод, что тактическая модель конкурентоспособности предприятий, оказывающих ресторанные услуги, ориентирована на условия совершенной конкуренции.

Рассматривая рыночный сегмент, в котором работают и оказывают услуги частные школы футбола (например, такие как «Футбольная школа Андрея Тихонова», «Футбольная Академия Егора Титова», «Чемпионика») необходимо обратить внимание на ключевое отличие их тактических моделей конкуренции от рынка ресторанных услуг, связанное с отношениями несовершенной конкуренции в сегменте спортивной подготовки молодого поколения.

Несовершенная конкуренция обусловлена тем фактом, что рынок физкультурно-спортивных услуг является формой связи между представителями субъектов сферы физической культуры и спорта и населением, которое нуждается в этих услугах, таким образом, в связи с социальной значимостью, данный вид услуг спонсируют органы власти различного уровня, а это в свою очередь приводит к тому, что субъектами рынка чаще выступают некоммерческие организации [3]. Особенность этих организаций заключается в том, что в своей деятельности они не нацелены на получение прибыли от предоставления физкультурно-спортивных услуг, а ориентируются на формирование социального имиджа, укрепление здоровья и привлечение населения к систематическим занятиям физической культурой и спортом [4].

Таблица 1.

Особенности конкуренции в различных отраслях

\begin{tabular}{|c|c|c|c|c|}
\hline Отрасль & Структура конкуренции & $\begin{array}{l}\text { Происхождение, тип конку- } \\
\text { рентных преимуществ }\end{array}$ & $\begin{array}{c}\text { Критерии конкуренто-спо- } \\
\text { собности }\end{array}$ & $\begin{array}{c}\text { Средство формирования } \\
\text { конкурентных преимуществ }\end{array}$ \\
\hline Сфера ресторанных услуг & Совершенная конкуренция & $\begin{array}{c}\text { Технологические пре- } \\
\text { имущества, уникальность } \\
\text { продукта, процессов, услуг }\end{array}$ & Затраты, качество, скорость & $\begin{array}{c}\text { Дифференциация } \\
\text { продукцции, услуг реклама, } \\
\text { брендинг }\end{array}$ \\
\hline Обучение футболу & $\begin{array}{c}\text { Несовершенная конку- } \\
\text { ренция с признаками } \\
\text { олигополии }\end{array}$ & $\begin{array}{l}\text { Технологические преимуще- } \\
\text { ства, авторский поход, бренд }\end{array}$ & $\begin{array}{c}\text { Качество, затраты, состав } \\
\text { тренеров }\end{array}$ & $\begin{array}{c}\text { Инновационные подходы в } \\
\text { обучении, качество, цена }\end{array}$ \\
\hline
\end{tabular}


Очевидно, что конкуренция школ массового футбола, функционирующих как частные, коммерческие структуры, в отличие от заведений питания, относящихся к аналогичному типу ведения бизнеса, но работающих на рынке совершенной конкуренции, ключевым образом отличается, поскольку в связи с участием государства полностью нивелируется ценовой фактор рыночной борьбы. В таких условиях футбольным школам приходится использовать качественные, инновационные детерминанты обеспечения конкурентных позиций, тогда как заведениям питания для достижения преимуществ иногда просто достаточно предложить клиентам более лояльные цены.

Если же рассматривать конкуренцию только частных школ массового футбола между собой, тогда можно констатировать факт схожих ценовых черт тактических моделей конкурентоспособности сферы ресторанных услуг и спорта. Кроме ценового фактора, общими чертами также является непосредственная зависимость от потребительского спроса; значимость пространственных и трудовых ресурсов; разветвленность состава конкурентов; высокий уровень риска ведения деятельности.

При этом, учитывая широкий спектр школ частного футбола, о которых уже упоминалось ранее, а также значительную популярность заведений питания, на сегодняшний день ценовая конкуренция и конкуренция качества в этих сегментах уже отходят на второй план, ведь заведения предлагают блюда и услуги примерно одинакового качества по примерно одинаковой цене.

Соответственно этот факт предопределяет разницу в объектах маркетинга, составляющего основу тактической модели конкурентоспособности. Так, успех ресторана зависит от наличия хорошего менеджмента, современной кухни, наличия концепции заведения питания, безупречного сервиса, интересного интерьера и разумных цен [5].

А преимущества футбольных школ, особенно авторских, на фоне конкурентов заключаются в присутствии ряда следующих объектов: наличие спортивных, сопутствующих товаров с символикой или отличительными знаками тренера, спектр и разнообразие предлагаемых физкультурно-спортивных услуг, внешняя и внутренняя среда школы, уровень и популярность личности, с которой ассоциируется школа, общая идея подготовки.

Из числа схожих элементов тактических моделей конкурентоспособности рассматриваемых субъектов экономики представляется целесообразным также обратить внимание на маркетинг персоналий. В маркетинге персоналий, как футбольных школ, так и ресторанов акцент делается на коммуникационной составляющей рыночной деятельности: личные контакты (возможность пообщаться со знаменитым игроком или известным шеф-поваром), направленные на популярность предлагаемых услуг, формирование и поддержку положительного имиджа. Это создает предпосылки для выигрышного позиционирования, создания и расширения спроса, привлечения внимания заинтересованных сторон (потенциальных потребителей, деловых партнеров, меценатов и т. д.), установления с ними партнерских отношений и заключения выгодных сделок.

\section{ЛИТЕРАТУРА}

1. Гашимова Л.Г., Магомедова А.М. Направления повышения уровня конкурентоспособности предприятия // Экономика и предпринимательство. 2020. №4(117). С. 1019-1021.

2. Рубин Ю.Б. Тактические модели и операции в конкуренции Современная конкуренция / 2015. Том 9. № 3 (51). С. 82-142.

3. Кузовлева И.Ю. Конкурентные особенности в сфере спортивных услуг // Экономика и предпринимательство. 2018. № 8. С. 705-708.

4. Манжелей И.В., Колунин Е.Т., Куценко Г.А. Воспитательный потенциал спортивной среды школы олимпийского резерва // Теория и практика физической культуры. 2019. №1. С. 94-96.

5. Раков А.В. Управление ресторанным бизнесом в условиях конкуренции // Экономика и предпринимательство. 2019. № 10. С. 617-620.

( К Краснова Марина Юрьевна (iamkrasnova@mail.ru), Ахмедова Римма Рафаильевна (rimma.akhmedova@gmail.com). Журнал «Современная наука: актуальные проблемы теории и практики» 